\title{
CONFERENCE ON OPTICS
}

\section{$M R S$ cooperates in 26th international meeting}

The Society was one of the cooperating organizations supporting the 26th Annual International Technical Symposium and Instrument Display of the Society of PhotoOptical Instrumentation Engineers (SPIE), held in San Diego Aug. 2227.

SPIE's symposia committee chairman, Robert E. Fischer of Hughes Aircraft Company, said the meeting offered eighteen technical conferences and twenty four tutorials on advances in optical and electrooptical applied science and engineering. More than one hundred fifty manufacturers and distributors exhibited their wares.

\section{Concurrent Congress \\ SPIE's meeting}

concurrently with the 15th International Congress on High Speed Photography and Photonics, an event held every two or three years and originally organized by the Society of Motion Picture and Television Engineers. Its scope has expanded enormously since the first congress was held in 1952, and organizers say the Proceedings of the congress form the primary record of scientific achievement in this field.

\section{Optical conference}

SPIE's Fischer said his group's meeting encompassed such materials-related topics as the industrial and commercial applications of holography, fiber optics, lasers, digital image processing, scattering was held and cryogenically cooled sensors.
Tutorials of interest to MRS members included infrared detection mosaic focal plane technology, optical measurements of thin films, optical materials and fundamentals of polymeric resist materials. A number of MRS members are also members of SPIE.

Among thu other associations that cooperated with SPIE in the meeting were the American Society of Photogrammetry, the IEEE Computer Society, the American Society for Laser Medicine and Surgery, the American Institute of Aeronautics and Astronautics, and the Institute for Biomedical Engineering Research. The University of Akron and Northeastern Ohio University's College of Medicine also supported the meeting. 